\title{
The Characteristics of Breast Cancer Mortality in Inner Mongolia between 2008 and 2010
}

\author{
Yueling Hu${ }^{1}$, Yun Li1', Wenrui Wang'2, Yonggang Qian², Chunxia Hui², Kepeng Xin', \\ Shiqi Wang1, Juan Sun ${ }^{*}$ \\ ${ }^{1}$ Department of Preventive Medicine, Inner Mongolia Medical University, Hohhot, China \\ ${ }^{2}$ Inner Mongolia Center for Disease Control and Prevention, Hohhot, China \\ Email: *nsunjuan@aliyun.com
}

Received 20 May 2014; revised 20 June 2014; accepted 20 July 2014

Copyright (C) 2014 by authors and Scientific Research Publishing Inc.

This work is licensed under the Creative Commons Attribution International License (CC BY).

http://creativecommons.org/licenses/by/4.0/

(c) (i) Open Access

\section{Abstract}

Background: The aim of this study was to explore the characteristics of breast cancer mortality in Inner Mongolia, and to provide evidence for the prevention of female breast cancer. Methods: Using data from the Death Registry System from 2008 to 2010. We classified female cancer deaths according to the International Classification of Disease-10th Revision. The mortality of different age groups and the potential years of life lost were calculated for female breast cancer in Inner Mongolia. Results: Breast cancer mortality for Inner Mongolian women was higher in older age groups. The potential years of life lost were also much higher in younger groups than in older groups. Marital status, education level and occupation may contribute to this increase in breast cancer mortality in younger groups. Conclusion: Preventive policies should be implemented to develop strategies aimed at reducing the breast cancer mortality, especially with regard to younger age groups in Inner Mongolia.

\section{Keywords}

Breast Cancer, Mortality, PYLL

\section{Introduction}

Breast cancer is the second most common cancer worldwide, and by far, the most common cancer in women, with an estimated 458,000 deaths (14\% of all cancers) having occurred in 2008 [1]. At the end of the last cen-

*Corresponding author.

How to cite this paper: Hu, Y.L., Li, Y., Wang, W.R., Qian, Y.G., Hui, C.X., Xin, K.P., Wang, S.Q. and Sun, J. (2014) The Characteristics of Breast Cancer Mortality in Inner Mongolia between 2008 and 2010. Open Journal of Epidemiology, 4, 135-140. 
tury in Japan, several studies had predicted that breast cancer would become a leading cancer [2]. Generally speaking, mortality of breast cancer are higher in North America, Northern Europe, Australia/New Zealand and lower in sub-Saharan Africa and Asia [3].

The age groups trend was different for breast cancer mortality in different countries and regions. In North America, breast cancer mortality rose with age. In Asian countries, the breast cancer mortality curves are flatter in younger age groups than in North America. The peak of mortality for age group was in 55 - 64 years groups in Asian [4]. Some studies showed that a higher proportion of breast cancer patients in developing Asian countries are more in younger age groups than those in developed Asian and Western countries [5]. This characteristic has been explained in part by the fact that many Asian women with breast cancer continue to be diagnosed at a relatively late stage, and young age by itself is a known indicator of poor prognosis for breast cancer [5].

Inner Mongolia is 1 of 5 minority ethnic autonomous regions in China. Until now, only a few studies have evaluated breast cancer in this region. The aim of this study was to explore the characteristics of breast cancer mortality.

\section{Materials and Methods}

\subsection{Data Source}

Death data between January 2008 and December 2010 was collected for this study through the Death Registry System (DRS), which was established by the Ministry of Health of China and maintained by the Inner Mongolia Autonomous Region Centers for Disease Control and Prevention (CDC). Death data from DRS included information on primary cause of death, death date, sex, and age. DRS uses a multistage cluster probability sampling strategy with stratification according to population structures of the eastern, central, and western regions of Inner Mongolia, the local gross domestic product, the proportion of rural dwellers, and the total population of local areas. Monitoring points of DRS in Inner Mongolia included Kailu County, Bairin Youqi, Sonid Youqi, Muslims District, and Linhe District.

The death data were categorized on the basis of the Tenth Revision of the International Classification of Diseases (ICD-10) criteria. The ICD-10 codes for breast cancer and female cancer used in this study were as follows: C50, malignant neoplasm of the breast; C51, malignant neoplasm of the vulva; C52, malignant neoplasm of the vagina; C53, malignant neoplasm of the cervix uteri; C54, malignant neoplasm of the corpus uteri; C55, malignant neoplasm of the uterus, part unspecified; C56, malignant neoplasm of the ovary; and C57, malignant neoplasm of other and unspecified female genital organs.

The total population in 2008-2010 was obtained from the Inner Mongolia CDC to calculate breast cancer mortality per 100,000 women aged 20 years or older.

All hospitals in Inner Mongolia were divided into 4 levels: provincial, municipal, county, and township. Pathological diagnosis can be provided in all 4 hospital levels. All diagnostic methods in this study included pathological, clinical, surgical, and postmortem diagnoses. Clinical diagnosis included imaging, pathological anatomy diagnosis, and pathophysiology diagnoses. Surgical and postmortem diagnoses were also employed.

\subsection{Statistical Analysis}

The chi-square test was used for examining the 5 monitoring points and 3-year differences in female cancer and breast cancer mortality. The percentage of hospital-level diagnoses and diagnostic methods was calculated. Life expectancies were estimated from life tables. These life tables were constructed from total mortality and population data, each covering 1 calendar year. In order to analyze the characteristics of age, patients were categorized into the younger age groups ( 20 - 49 years old) and older age groups ( $\geq 50$ years). We calculated the potential years of life lost (PYLL) for female cancer and breast cancer for the premature death analysis for all ages. To compare potential relevant factors between younger and older age groups, the mortality by region, ethnicity, marital status, occupation and education level for female cancer and breast cancer were calculated. The chisquare test was used to examine the differences of these rates.

Microsoft Excel and SPSS 13.0 statistical software were used for data management and analysis. A $p$-value of $\leq 0.05$ was considered statistically significant throughout this study.

\section{Results}

The annual average population of the 5 monitoring points was 1.5 million, with $60 \%$ of the people living in rural 
areas. Populations of the 5 monitoring points accounted for about $6 \%$ of the total population of Inner Mongolia. There were a total of 362 cancer deaths among women recorded in the DRS system during 2008 - 2010. The mortality was 22/100,000 (95\% confidence interval [CI], 19.7 - 24.3) for female cancer and 10/100,000 (95\% CI, 8.5 - 11.1) for breast cancer.

Table 1 shows the mortality for female cancer and breast cancer in the 5 monitoring points according to the calendar period. Breast cancer mortality accounted for nearly half of the female cancer deaths during those 3 years. A large variation in mortality for female cancer (16.0, 95\% CI, 4.0 - 29.0) and breast cancer, (95\% CI, 5.4 - 14.7) was observed during the 3 years. However, there were no statistically significant differences in the 3 years between the 5 monitoring points of female cancer $\left(\chi^{2}=13.6, p=0.09\right)$ and breast cancer $\left(\chi^{2}=11.2, p=\right.$ 0.19). Therefore, the data sets for the 3 years and 5 monitoring points were merged for analysis.

The percentage of hospital-level diagnoses and diagnostic methods for female cancer and breast cancer are shown in Table 2. More than $80 \%$ of women were diagnosed in the first 2 hospital levels. All cases of breast cancers and $99.7 \%$ of female cancers were diagnosed pathologically.

Table 1. Mortality rate of female cancer and breast cancer among the 5 monitoring points in Inner Mongolia (2008-2010).

\begin{tabular}{ccccccc}
\hline & \multicolumn{2}{c}{$\mathbf{2 0 0 8}$} & \multicolumn{2}{c}{$\mathbf{2 0 0 9}$} & \multicolumn{2}{c}{$\mathbf{2 0 1 0}$} \\
\hline Female cancer & $\mathrm{n}$ & rate $\left(1 / 10^{5}\right)$ & $\mathrm{n}$ & rate $\left(1 / 10^{5}\right)$ & $\mathrm{n}$ & rate $\left(1 / 10^{5}\right)$ \\
\hline Kailu County & 11 & 7.67 & 21 & 14.5 & 16 & 10.9 \\
Balinyouqi & 7 & 10.6 & 14 & 20.9 & 13 & 19.1 \\
Suniteyouqi & 8 & 29.3 & 2 & 7.2 & 3 & 10.7 \\
Muslims District & 18 & 16.3 & 33 & 29.7 & 22 & 19.7 \\
Linhe District & 70 & 35.9 & 66 & 33.4 & 58 & 29.0 \\
Total & $\mathbf{1 1 4}$ & $\mathbf{2 1 . 0}$ & $\mathbf{1 3 6}$ & $\mathbf{2 4 . 8}$ & $\mathbf{1 1 2}$ & $\mathbf{2 0 . 2}$ \\
Breast cancer & & & & & & \\
Kailu County & 5 & 3.49 & 14 & 9.65 & 5 & 3.40 \\
Balinyouqi & 1 & 1.52 & 5 & 7.46 & 5 & 7.33 \\
Suniteyouqi & 3 & 11.0 & 2 & 7.24 & 2 & 7.16 \\
Muslims District & 12 & 10.9 & 17 & 10.8 & 11 & 9.83 \\
Linhe District & 36 & 18.5 & 27 & 13.7 & 20 & 10.0 \\
Total & $\mathbf{5 7}$ & $\mathbf{1 0 . 5}$ & $\mathbf{6 5}$ & $\mathbf{1 1 . 9}$ & $\mathbf{4 3}$ & $\mathbf{7 . 7 5}$ \\
\hline
\end{tabular}

Table 2. Percentage of the breast cancer and female cancer in the 5 monitoring points (20082010).

\begin{tabular}{ccccc}
\hline & \multicolumn{2}{c}{ Breast cancer } & \multicolumn{2}{c}{ Female cancer } \\
\hline Highest diagnostic institutions & $\mathbf{n}$ & $\mathbf{\%}$ & $\mathbf{n}$ & \% \\
\hline Provincial hospital & & & & 37.3 \\
Municipal hospital & 75 & 45.5 & 135 & 50.6 \\
County level hospital & 72 & 43.6 & 183 & 11.3 \\
Township level hospital & 17 & 10.3 & 41 & 0.83 \\
Diagnostic method & 1 & 0.61 & 3 & 39.5 \\
Clinical and Pathology & & & 143 & 24.9 \\
Pathology & 67 & 40.6 & 90 & 17.7 \\
Clinical & 49 & 29.7 & 64 & 17.4 \\
Surgery & 20 & 12.1 & 63 & 0.28 \\
\hline Postmortem infer & 28 & 17.0 & 1 & 0.28 \\
\hline
\end{tabular}


The PYLL and the mortality in the 5 monitoring points are presented in Figure 1. Points to the up of the column indicate causes that contribute to PYLL more than to mortality. Error bars represent the standard error of mortality. Figure 1 shows that the PYLL value of breast cancer and female cancer was close to the standard error of corresponding mortality. It means that the PYLL had a similar effect as mortality. Figure 2 shows the PYLLs of breast cancer and female cancer were significantly higher than the mortality in younger age groups. Conversely, the mortality was slightly higher in older groups. It is consistent with the rule of PYLL and mortality of cancer.

The demographic characteristics for female cancer and breast cancer are presented in Table 3. The rates of younger age groups were higher than older age groups in all categories. The chi-square test indicates that the rates of marital status and education level in younger age groups were higher than that in older age groups. This means that the risk of female cancer and breast cancer increased $(p<0.05)$. Although occupation was not a significant factor in female cancer $(p=0.06)$, it was close to the significance level and was significant in breast cancer $(p<0.01)$.

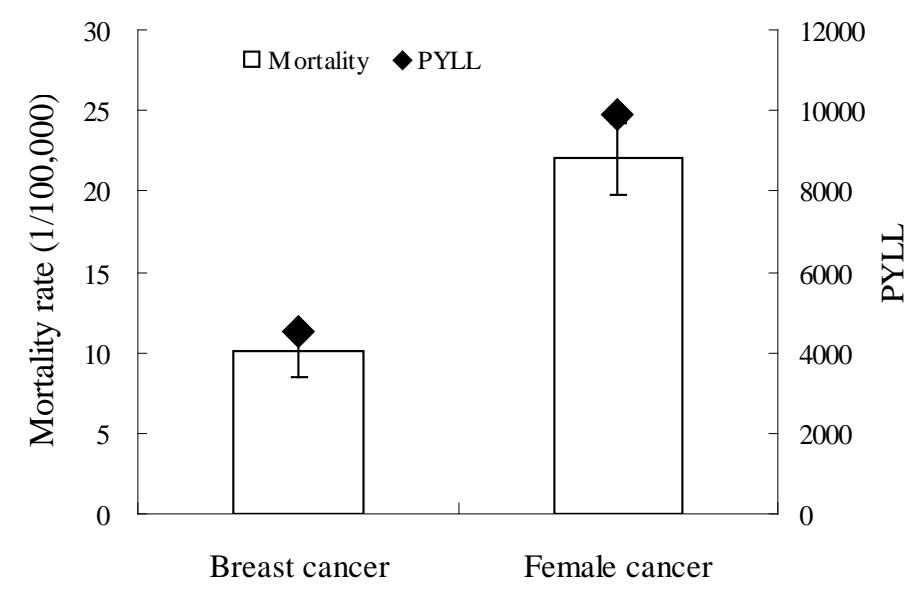

Figure 1. Comparison of mortality to PYLL in five monitoring points from 2008 to 2010 .

Table 3. Results of the Chi-square test for characteristic variables and corresponding rates for female cancer and breast cancer in the 5 monitoring points (2008-2010).

\begin{tabular}{|c|c|c|c|c|c|c|}
\hline \multirow[t]{2}{*}{ Category } & \multicolumn{2}{|c|}{$<50$} & \multicolumn{2}{|c|}{$\geq \mathbf{5 0}$} & \multirow[t]{2}{*}{$\chi^{2}$} & \multirow[t]{2}{*}{$p$} \\
\hline & $\mathbf{n}$ & Rate (\%) & $\mathbf{n}$ & Rate (\%) & & \\
\hline \multicolumn{7}{|l|}{ Female cancer } \\
\hline Urban & 96 & 61.2 & 112 & 54.6 & 1.54 & 0.21 \\
\hline National minority & 13 & 8.28 & 15 & 7.32 & 0.12 & 0.73 \\
\hline Cohabit & 148 & 94.3 & 170 & 82.9 & 10.7 & $0.01^{*}$ \\
\hline Employment & 115 & 73.3 & 131 & 63.9 & 3.57 & 0.06 \\
\hline Above middle school levels & 114 & 72.6 & 64 & 31.2 & 68.5 & $0.00^{* *}$ \\
\hline \multicolumn{7}{|l|}{ Breast cancer } \\
\hline Urban & 47 & 63.5 & 48 & 52.8 & 1.94 & 0.16 \\
\hline National minority & 5 & 6.76 & 5 & 5.49 & 0.11 & 0.74 \\
\hline Cohabit & 70 & 94.6 & 74 & 81.3 & 6.48 & $0.01^{*}$ \\
\hline Employment & 71 & 96.0 & 54 & 59.3 & 29. 8 & $0.00^{* *}$ \\
\hline Above middle school levels & 55 & 74.3 & 23 & 25.3 & 39.4 & $0.00^{* *}$ \\
\hline \multicolumn{7}{|l|}{${ }^{*} p<0.05$} \\
\hline${ }^{* *} p<0.01$ & & & & & & \\
\hline
\end{tabular}




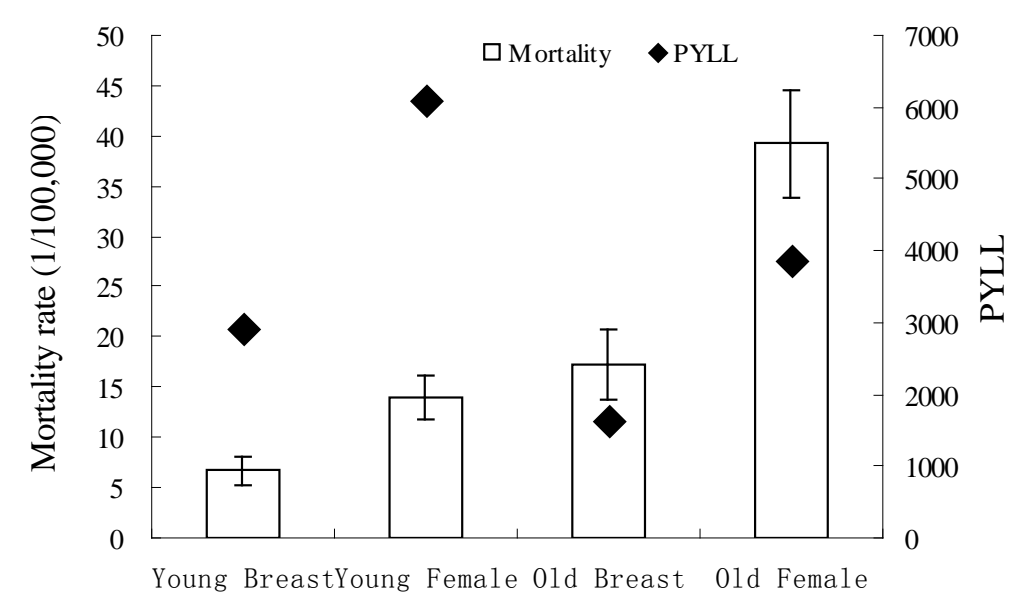

Figure 2. Comparison of mortality to PYLL by younger and older groups in five monitoring points from 2008 to 2010.

\section{Discussion}

Our results show that the breast cancer mortality were 10/100,000. It was lower compared to recently reported breast cancer mortality in Western countries; 22.7/100,000 in Serbia [6] and 21.8/100,000 in Ireland [1]. However, it was higher than that in neighbouring regions of Mongolia $(2.80 / 100,000)$ [7]. The breast cancer mortality increased with age in Inner Mongolia.

Both the PYLL and mortality include some measure of the number of deaths and distribution of age at death, although they have different emphasis. The PYLL contribution of breast cancer was similar to mortality. The PYLL contribution of breast cancer greatly exceeds the mortality in younger age groups and was less than the mortality in older age groups. It was indicated that the impact of loss of life for breast cancer was more severe for younger age groups. In contrast, the impact of mortality was more severe for older age groups. It was consistent with the general rule in PYLL and mortality of cancer [8].

We selected some demographic characteristics to explore their effect for age of breast cancer. In our study, the mortality for living with a spouse was higher in younger age groups than in older age groups among the cases of breast cancer deaths. Women who lived together with a spouse were more likely to develop breast cancer than those who live alone owing to the widowed or divorced status. Consistent with our study, women who lived alone had lower breast cancer mortality in Norway [9] and Sweden [10].

In our study, the rates of higher education in young groups were almost 3 times higher than in older age groups with breast cancer. Some earlier studies in the West have shown the breast cancer mortality in women who had higher education were higher [11]. Early in the 1990s some studies have shown that higher education in itself being a risk factor for breast cancer was unlikely. The biologic factors hypothesized to mediate this relation, such as nulliparity or an older age at first birth among more highly educated women partially explained the excess risk among the most highly educated group [12]. The higher breast cancer risk seen among well-educated woman appears to be attributable to these women's greater exposure to breast cancer risk factors [12]. Older age at first birth increases the risk for breast cancers [13].

In our study, the rates of employment were more than $90 \%$ in younger groups and less than $60 \%$ in older groups. Some studies have shown the breast cancer mortality in women who were employed were higher than those who never work [14]. The retirement age for women was 50 years according to State Council on the workers retire or resign Interim Measures. Many retired women had less work stress. Some studies showed high levels of strain were associated with a slight increase in the risk of breast cancer [15].

\section{Conclusion}

The present study demonstrated that breast cancer mortality increased with age. Young women who lived together with a spouse, had a job and had higher education were more likely to die of breast cancer. Control policies should aim at reducing the breast cancer mortality for younger age groups. Additional research needs to be conducted to identify characteristics for different populations to better design strategies to minimize the impact 
on breast cancer death in younger age groups.

\section{Acknowledgments}

Inner Mongolia Medical University Technology million project, No.NY2011BW006; Natural Science Foundation of Inner Mongolia in China (2013MS1124); Inner Mongolia Autonomous Region Colleges and Universities of Science and Technology Research Projects, No. NJZY13415.

\section{Conflicts of Interest Statement}

The authors declare that they have no competing interests.

\section{References}

[1] Ferlay, J., Shin, H.-R., Bray, F., Forman, D., Mathers, C. and Parkin, D.M. (2010) Estimates of Worldwide Burden of Cancer in 2008: Globocan 2008. International Journal of Cancer, 127, 2893-2917. http://dx.doi.org/10.1002/ijc.25516

[2] Tominaga, S. and Kuroishi, T. (1999) Epidemiology and Prevention of Breast Cancer in the 21st Century. Breast Cancer, 6, 283-288.

[3] Jemal, A., Center, M.M., DeSantis, C. and Ward, E.M. (2010) Global Patterns of Cancer Incidence and Mortality Rates and Trends. Cancer Epidemiology Biomarkers \& Prevention, 19, 1893-1907. http://dx.doi.org/10.1158/1055-9965.EPI-10-0437

[4] Curado, M.P. (2011) Breast Cancer in the World: Incidence and Mortality. Salud Pública de México, 53, $372-384$.

[5] Agarwal, G., Pradeep, P.V., Aggarwal, V., Yip, C.-H. and Cheung, P.S.Y. (2007) Spectrum of Breast Cancer in Asian Women. World Journal of Surgery, 31, 1031-1040. http://dx.doi.org/10.1007/s00268-005-0585-9

[6] Mihajlović, J., Pechlivanoglou, P., Miladinov-Mikov, M., Živković, S. and Postma, M.J. (2013) Cancer Incidence and Mortality in Serbia 1999-2009. BMC Cancer, 13, 18. http://dx.doi.org/10.1186/1471-2407-13-18

[7] Sandagdorj, T., Sanjaajamts, E., Tudev, U., Oyunchimeg, D., Ochir, C. and Roder, D. (2010) Cancer Incidence and Mortality in Mongolia-National Registry Data. Asian Pacific Journal of Cancer Prevention, 11, 1509-1514.

[8] Kono, A., Misumi, J. and Misumi, J. (2005) The Time Trend of Breast Cancer Mortality in Japan. Archives of Gynecology and Obstetrics, 272, 187-190. http://dx.doi.org/10.1007/s00404-004-0719-6

[9] Hemminki, K. and Jiang, Y. (2002) Life Style and Cancer: Effect of Divorce. International Journal of Cancer, 98, 316-319. http://dx.doi.org/10.1002/ijc.10195

[10] Hemminki, K. and Li, X. (2003) Lifestyle and Cancer: Effect of Widowhood and Divorce. Cancer Epidemiology, Biomarkers Prevention, 12, 899-904.

[11] Huisman, M., Kunst, A.E., Bopp, M., Borgan, J.-K., Borrell, C., Costa, G., Deboosere, P., Gadeyne, S., Glickman, M., Marinacci, C., Minder, C., Regidor, E., Valkonen, T. and Mackenbach, J.P. (2005) Educational Inequalities in CauseSpecific Mortality in Middle-Aged and Older Men and Women in Eight Western European Populations. The Lancet, 365, 493-500. http://dx.doi.org/10.1016/S0140-6736(05)17867-2

[12] Heck, K.E. and Pamuk, E.R. (1997) Explaining the Relation between Education and Postmenopausal Breast Cancer. American Journal of Epidemiology, 145, 366-372. http://dx.doi.org/10.1093/oxfordjournals.aje.a009114

[13] Merrill, R.M., Fugal, S., Novilla, L.B. and Raphael, M.C. (2005) Cancer Risk Associated with Early and Late Maternal Age at First Birth. Gynecologic Oncology, 96, 583-593. http://dx.doi.org/10.1016/j.ygyno.2004.11.038

[14] Ekpanyaskul, C., Khuhaprema, T., Wiangnon, S. and Sangrajrang, S. (2010) Case-Control Study of Occupational Categories and Breast Cancer Risk in Thailand. Asian Pacific Journal of Cancer Prevention, 11, 793-797.

[15] Kuper, H., Yang, L., Theorell, T. and Weiderpass, E. (2007) Job Strain and Risk of Breast Cancer. Epidemiology, 18, 764-768. http://dx.doi.org/10.1097/EDE.0b013e318142c534 
Scientific Research Publishing (SCIRP) is one of the largest Open Access journal publishers. It is currently publishing more than 200 open access, online, peer-reviewed journals covering a wide range of academic disciplines. SCIRP serves the worldwide academic communities and contributes to the progress and application of science with its publication.

Other selected journals from SCIRP are listed as below. Submit your manuscript to us via either submit@scirp.org or Online Submission Portal.
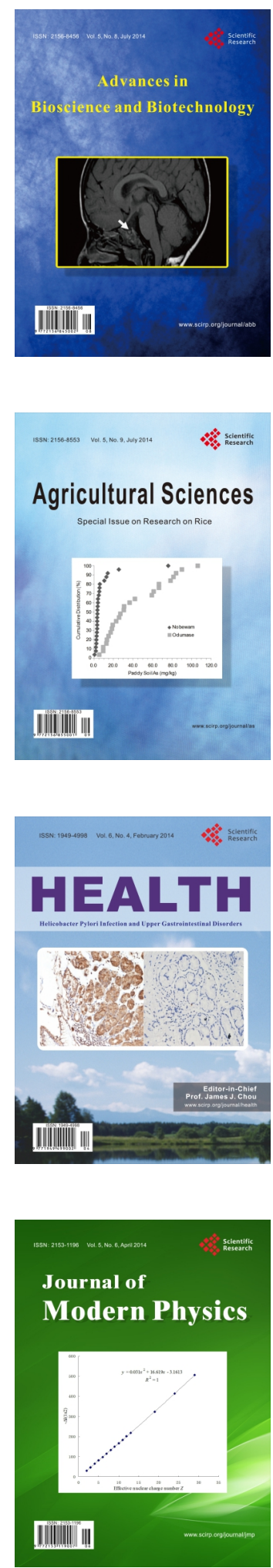
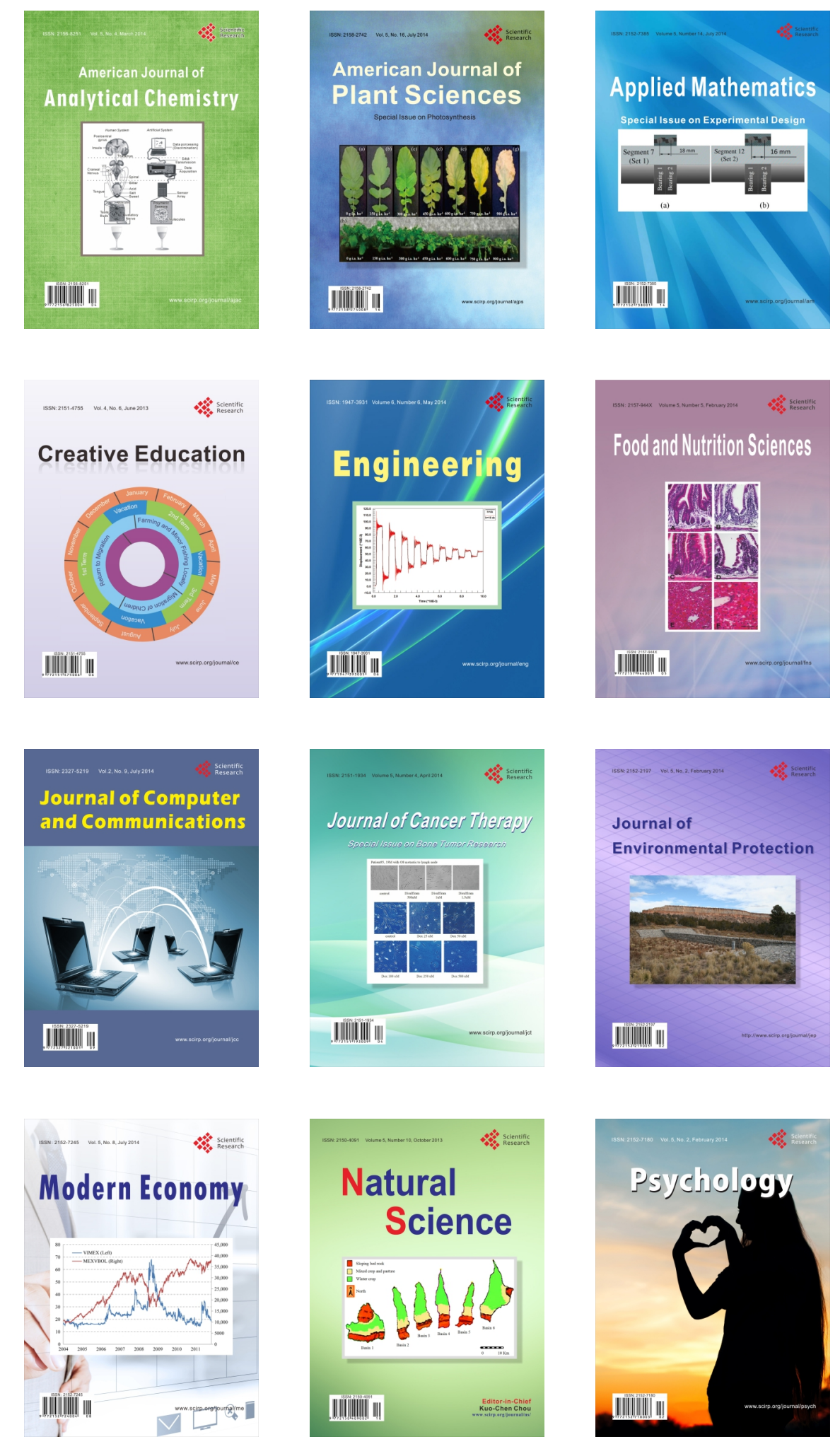